WP 53_11

\author{
Elettra Agliardi \\ University of Bologna, Italy \\ The Rimini Centre for Economic Analysis, Italy \\ Luigi Sereno \\ University of Bologna, Italy
}

\title{
ENVIRONMENTAL PROTECTION, PUBLIC FINANCE REQUIREMENTS AND THE TIMING OF EMISSION REDUCTIONS
}

Copyright belongs to the author. Small sections of the text, not exceeding three paragraphs, can be used provided proper acknowledgement is given.

The Rimini Centre for Economic Analysis (RCEA) was established in March 2007. RCEA is a private, nonprofit organization dedicated to independent research in Applied and Theoretical Economics and related fields. RCEA organizes seminars and workshops, sponsors a general interest journal The Review of Economic Analysis, and organizes a biennial conference: The Rimini Conference in Economics and Finance (RCEF). The RCEA has a Canadian branch: The Rimini Centre for Economic Analysis in Canada (RCEACanada). Scientific work contributed by the RCEA Scholars is published in the RCEA Working Papers and Professional Report series.

The views expressed in this paper are those of the authors. No responsibility for them should be attributed to The Rimini Centre for Economic Analysis. 


\title{
Environmental protection, public finance requirements and the timing of emission reductions
}

\author{
Elettra Agliardi ${ }^{1 *} \quad$ Luigi Sereno ${ }^{2}$ \\ ${ }^{1}$ Department of Economics, University of Bologna and Rimini Center for Economic \\ Analysis \\ Piazza Scaravilli 2, 40126 Bologna, Italy. \\ 2 Department of Economics, University of Bologna \\ Piazza Scaravilli 2, 40126 Bologna, Italy.
}

\begin{abstract}
The effects of four environmental policy options for the reduction of pollution emissions, i.e. taxes, emission standards, auctioned permits and freely allocated permits, are analyzed. The setup is a real option model where the amount of emissions is determined by solving the firm's profit maximization problem under each policy instrument. The regulator solves an optimal stopping problem in order to find the critical threshold for policy adoptions taking into account revenues from taxes and auctioned permits and government spending. In this framework, we find the ranking of the alternative policy options in terms of their adoption lag and social welfare. We show that when the output demand is elastic emission standards are preferred to freely allocated permits. Taxes and auctioned permits are always equivalent in terms of their adoption lag and social welfare and also equivalent to emission standards when the regulator redistributes revenues.
\end{abstract}

Key words: Environmental policies; Taxes; Emission standards; Permits; Public abatement spending; Optimal implementation time; Real options

JEL Classification: Q28; Q 48; L51; H23

\footnotetext{
*Corresponding authors. E-mail addresses: elettra.agliardi@unibo.it (E. Agliardi), luigi.sereno@unibo.it (L. Sereno).
} 


\section{Introduction}

Policy instruments to promote environmental protection can take various forms and include official restrictions and positive incentives designed to control activities that may be harmful to the quality of environment. Taxes and subsidies can be effective to encourage compliance with environmental policy. Tradable emission permits allow the government to give companies licenses to pollute as much as they wish to the extent that they pay the price. Thus, companies can buy, sell and exchange these permits in a market. Other environmental policy instruments include legislations enacted to prohibit the use of certain harmful substances, set limits on emissions, enforce certain technical standards, limit some activities in special areas such as nature reserves or car-free areas in cities and control land use planning. All the listed environmental policies are usually welfare distorting and thus it becomes relevant to rank alternative policy options and assess their relative desirability in terms of environmental quality and social welfare.

In this paper the effects of four environmental policy options for the reduction of pollution emissions, i.e. taxes, emission standards, auctioned permits and freely allocated permits, are analyzed. The setup is a real option model where the adoption timing of each policy instrument is analyzed. Our work endogenously takes into account the level of emissions before and after the adoption of the new environmental policy. The level of emissions is determined for each policy instrument by solving the profit maximization problem of a duopolistic firm under Cournot competition. The regulator solves an optimal stopping problem in order to find the critical threshold for policy adoptions taking into account revenues from taxes and auctioned permits and government spending. In particular, we specify two possible fiscal policy decisions. In the former, the government revenues generated by pollution taxes and auctioned permits are redistributed to the firms and the consumers, while in the latter the collected revenues are used to finance pollution abatement activities.

Our paper improves on the current literature in several dimensions. To the best of our knowledge, this is the first paper where the public finance requirements of environmental protection is embedded in a real option framework about the timing of emission reductions. Moreover, in our model the regulator's objective function differs from the usual Pindyck (2000, 2002) social damage, because it takes into account both the firms' profits, the consumers' surplus, the social damage from pollution and the net governmental revenues from the environmental policies, allowing us to discuss the implications of the above policy interventions (i.e., taxes, emission standards, auctioned permits and freely allocated permits) from the point of view of social welfare. Our paper extends and generalize previous works on uncertainty affecting the policies to control pollution (i.e., Pindyck, 2000, 2002; Conrad, 2000; Saphores and Carr, 2000; Nishide and Ohyama, 2009; Xepapadeas, 2001; Van Soest, 2005) by considering an industry where firms compete à la Cournot, while the above-mentioned papers have been concerned with a purely decision theoretic framework. Since our analysis compares four policy instruments, it is also more exhaustive than 
most of them.

Our main results are that depending on the slope of output demand (i) the optimal adoption threshold under emission standards may be larger or lower than the adoption threshold under freely allocated permits, and (ii) the value of social welfare, which includes the option to implement the environmental policy to reduce emissions, under emission standards may be higher or lower than the value of social welfare under freely allocated permits. Taxes and auctioned permits are always equivalent in terms of their adoption lag and social welfare and also equivalent to emission standards when the regulator redistributes the revenues to society. Finally, through simulations we show that taxes and auctioned permits are less preferred policy instruments in the case of a regulator using the environmental policy revenues to finance public abatement activities.

The paper is organized as follows. Section 2 provides a literature review. Section 3 describes the setup of the model. Section 4 solves the optimal stopping problem of the environmental regulator and finds the rankings of the four environmental policies when the environmental policy revenue is redistributed to society (Propositions 1-4). Section 5 solves the optimal stopping problem of the environmental regulator and finds the rankings of the four environmental policies when the environmental policy revenues are used to finance abatement activities (Proposition 5-7). Numerical results are presented in Section 6. In particular, a detailed sensitivity analysis is shown as to deepen our understanding of the effects of environmental taxes, emission standards, auctioned permits and freely allocated permits on the optimal timing of emission reductions. Section 7 concludes the paper. All proofs are in the Appendix.

\section{Literature review}

There have been many studies on effective policy solutions to environmental degradation based on approaches that differ from the present paper. Most of them studied the impact of the policy choice on technological adoption. Coria (2009) studies how the choice between emission taxes, auctioned permits and freely allocated permits affects the pattern of adoption of an environmentalfriendly technology when firms engage in Cournot competition and the regulator commits to the ex post optimal environmental policy before firms begin to adopt the technology. In this framework she analyzes the impact of policy choice over the number of periods that elapsed until the new technology is introduced into the industry. Similarly, Montero (2002 a,b) evaluate the R\&D incentives to invest in abatement technologies when the regulator behaves myopically and investment incentives come from a "direct" effect and a "strategic" effect under different market conditions. Montero (2002 a,b) find a ranking supporting the use of taxes over emission standards and permits. Neither Montero (2002 a,b) nor Coria (2009) pay attention to the uncertainty regarding the timing and value of the new technology. Our industry analysis starts from Coria (2009) and Montero (2001 a,b), in that we assume a duopolistic market where firms com- 
pete in output and examine four environmental policies, but then we introduce uncertainty over the social costs of environmental damage and study the timing of policy planning and adoption.

Van Soest (2005) analyzes the impact of environmental taxes and quotas on the timing of adoption of energy-saving technologies under irreversibility and stochastic arrival rate of the new technologies, and shows that: (i) increased environmental stringency (measured in tax and its equivalent in terms of quota) does not necessarily induce early adoption, and (ii) there is no unambiguous ranking of policy instruments in terms of the length of the adoption lag. While Van Soest (2005) studies the investment decisions of a single polluting firm under environmental regulations that impose sunk costs on the firm, we consider interacting firms, a more exhaustive set of policy tools for abating emissions and the role of public finance on the decision between alternative policy instruments.

Our paper employs real option methodology. There are important reasons to use real options when dealing with the choice of policy options for emission reductions. Some papers have employed a cost-benefit analysis, where the social planner maximizes expected benefits from some policy to calculate the optimal level of current abatement of greenhouse gases, and hence the current social cost of carbon. However, as pointed out by Pindyck (2000, 2002), standard cost-benefit analysis fails to simultaneously capture the irreversibilities and uncertainties about climate change and environmental policy intervention. Irreversibilities can originate from the environmental damage caused by atmospheric GHG concentrations and also from the sunk cost of adopting policies to reduce emissions., e.g., to scrap obsolete technologies and adoption of new ones, improve automobile gas mileage, etc. Real options are also the appropriate methodology to incorporate the role of timing in policy adoption, and timing has been indicated as a most crucial issue in the current political agenda (see also the UN Framework Convention in Climate Change, 2011). Recently, a number of studies in the real options literature have examined the implications of irreversibility and uncertainty for the optimal timing problem of environmental policy adoption in different contexts (see, for example, Conrad (1997, 2000), Saphores and Carr (2000); Xepapadeas (2001), Insley (2003), Van Soest (2005), Wirl (2006); Ohyama and Tsujimura (2006); Nishide and Ohyama (2009); Balikcioglu, Fackler and Pindyck (2011); Travaglini and Saltari (2011), Agliardi and Sereno (2011)). However, none of them deals with interacting firms, nor addresses the issue of the public financing requirements of environmental protection.

Our paper builds on Pindyck (2000), although he does not look at the ranking of policy instruments for the control of pollution. He investigates how irreversibility influences the timing of policy planning and adoption in a framework with either ecological or economic uncertainty. While Pindyck (2000) considers the optimal timing for a single (unspecified) environmental policy adoption, we consider the timing of four policies and analyze the impact of public finance on the critical thresholds of adoptions.

Agliardi and Sereno (2011) study the effects of two environmental policy options for the reduction of pollution emissions. Their model endogenously 
takes into account the level of emissions before and after the adoption of the new environmental policy. The level of emissions is determined by solving the firm's profit maximization problem under taxes and fixed quotas, as in Van Soest (2005). They find that the optimal adoption threshold under taxes is always larger than the adoption threshold under fixed quota, even in a setting characterized by ecological uncertainty and ambiguity over future costs and benefits over adopting environmental policies. To introduce tradeable emission permits, we follow Coria (2009), and consider an industry composed of two firms that engage in Cournot competition in the output market. Moreover, in our model the regulator computes total benefits as the sum of aggregated profits, consumer surplus, social damage from pollution and revenues from each policy instruments. In contrast, Agliardi and Sereno (2011) consider the firm's profit and social damage only, while Coria (2009) does not take into account public revenue and government expenditures.

\section{The model}

We consider a market consisting of two profit-maximizing firms that produce a homogeneous product. The linear inverse demand function is

$$
p(Q)=a-b Q, \quad a, b>0,
$$

where $p$ is the output market price, $Q=q_{1}+q_{2}$ is the aggregate output and $q_{i}$ denotes the level of production of firm $i$.

Output production generates pollution and this damages the quality of the environment. Let $e_{i}$ denote the discharges of the $i$ th firm. To manage this emission, each firm installs an abatement technology. Following Coria (2009) and Montero (2002 a,b), we assume that the total abatement cost for each firm can be described as $c_{i} r_{i}^{2}$, where $c_{i}$ is an index of cost and $r_{i}$ is the quantity of emissions that firm $i$ reduces, that is:

$$
r_{i}=\left(q_{i}-e_{i}\right) .
$$

There are no further production costs. Firms are assumed to compete à la Cournot in the output market.

\subsection{The pollution process}

Let $M_{t}$ be a state variable that summarizes the stock of pollution, i.e., the average concentration of $\mathrm{CO}_{2}$ in the atmosphere or the acidity level of a lake, and let $E_{t}$ be the aggregate level of emissions, $E_{t}=e_{1, t}+e_{2, t}$, that controls $M_{t}$. The evolution of $M_{t}$ over time is assumed to follow the same differential equation in Pindyck (2000):

$$
d M_{t}=\left(E_{t}-\delta M_{t}\right) d t, \quad M_{0}=M
$$


where $\delta \in[0,1)$ is the rate of natural decay of the stock pollutant over time, i.e., a fraction $\delta$ of the pollutant in the atmosphere diffuses into the ocean, forests and soil.

We consider environmental policies which involve a one-time reduction in $E_{t}$. Specifically, we denote by $\tau$ the unknown adoption time of the new environmental policy and assume that the dynamics of $M_{t}$ changes after $\tau$ :

$$
d M_{t}=\left\{\begin{array}{c}
\left(E^{N}-\delta M_{t}\right) d t \text { for } 0 \leq t<\tau \\
\left(E^{A}-\delta M_{t}\right) d t \text { for } t \geq \tau
\end{array}\right.
$$

The superscripts $N$ and $A$ indicate the state of no-adoption and adoption of the new environmental policy, respectively. That means that until a policy is adopted $E_{t}$ stays at the constant initial level $E^{N}$, while policy adoption implies a one-time reduction to a new permanent level $E^{A}$, with $0 \leq E^{A}<$ $E^{N}$. Hence, $E^{A}$ quantifies the reduction of pollution growth induced by the abatement activities of the whole industry. Under this assumption, the speed of pollution accumulation is reduced by $E^{N}-E^{A}$, affecting positively the quality of the environment. In the next section we endogenously determine $E^{N}$ and $E^{A}$ by solving the firm's profit maximization problem under each policy instrument.

\subsection{The firm's profit maximization problem}

At any time, the firm $i$ has to decide about the optimal levels of emission $e_{i}$ and output $q_{i}$ to maximize the instantaneous operating profit $\pi_{i}$. In the absence of any environmental regulation, the operating profit of firm $i$ at time $t$ equals revenue minus the total abatement cost:

$$
\pi_{i}=p(Q) q_{i}-c_{i}\left(q_{i}-e_{i}\right)^{2}, \text { for } i=1,2
$$

The optimal levels of emission and output for each firm is given by the first order conditions (FOCs) for $e_{i}$ and $q_{i}$ :

$$
\begin{gathered}
2 c_{i}\left(q_{i}-e_{i}\right)=0 \\
p(Q)+p^{\prime}(Q) q_{i}-2 c_{i}\left(q_{i}-e_{i}\right)=0
\end{gathered}
$$

Eq. (4) says that, in the absence of any environmental regulation, production leads to $q_{i}$ units of emissions (i.e., $e_{i}=q_{i}$ ). Therefore, firm $i$ will not abate any pollution. Thus:

$$
q_{i}^{N}=\frac{a}{3 b}, e_{i}^{N}=\frac{a}{3 b} \text { and } \pi_{i}^{N}=\frac{a^{2}}{9 b}
$$


The profit maximization problem (3) allows us to determine the level of emissions $E_{t}$ before the adoption of the new environmental policy, that is,

$$
E^{N}=e_{1}^{N}+e_{2}^{N}
$$

We assume that the regulatory goal is to limit the quantity of industry emissions at some level $E^{A}$ by means of one of the following four environmental policy instruments: emissions taxes, standards, freely allocated tradeable permits and auctioned permits. To make instruments directly comparable we assume that, in the initial situation, the level of emissions is the same under all four regimes. Like Van Soest (2005), we assume that the environmental regulator has determined the Pigouvian tax $(\zeta)$ that equates the marginal benefits and costs of pollution. The emission target $E^{A}$ is then assumed to be equal to the amount of emissions that the firms will produce, given this tax rate. Hence, the objective of the environmental regulator is to cap the aggregate level of emissions at $E^{A}$ either by establishing standards for firms or by issuing tradeable permits to be distributed gratis or auctioned off. Under emission standards, firms' emissions are limited to $\bar{e}_{1}$ and $\bar{e}_{2}$ respectively, such that $\bar{e}_{1}+\bar{e}_{2}=E^{A}$. Under permits system, a total number of $E^{A}$ permits are either distributed freely, or auctioned off.

\subsection{Taxes}

In this section we compute the firm's operating profit under taxes and determine the level of emissions $E^{A}$ which serves as a benchmark for reduction of emissions. Under tax regulation and Cournot competition, each firm looks for the output and the mix of abatement plus tax payment that maximizes profits. If the environmental regulator has decided to charge a per unit fee equal to $\zeta$, then firm $i$ will maximize the following profit function:

$$
\left(\pi_{i}^{A}\right)^{\text {Taxes }}=\max _{e_{i}, q_{i}}\left\{p(Q) q_{i}-c_{i}\left(q_{i}-e_{i}\right)^{2}-\zeta e_{i}\right\}, \text { for } i=1,2
$$

The optimal level of emissions and output for each firm is given by the FOCs for $e_{i}$ and $q_{i}$ :

$$
\begin{gathered}
2 c_{i}\left(q_{i}-e_{i}\right)=\zeta, \\
p(Q)+p^{\prime}(Q) q_{i}-2 c_{i}\left(q_{i}-e_{i}\right)=0 .
\end{gathered}
$$

Eq. (7) indicates that at the optimum, each firm faces a marginal abatement cost equal to the emission tax $\zeta$. Combining the the FOCs for $e_{i}$ and $q_{i}$, we have:

$$
p(Q)+p^{\prime}(Q) q_{i}=\zeta
$$

The term on the left-hand side in Eq. (8) is the marginal benefit of production, while the term on the right-hand side is the marginal abatement cost. At the 
optimum, each firm faces a benefit per unit of output equal to the tax $\zeta$. The optimal level of output of the two firms is:

$$
q_{i}^{A}=\frac{a-\zeta}{3 b},
$$

where it is assumed that $a>\zeta$ in order for equilibrium quantities to be positive. Moreover, each individual firm's optimal level of emission under taxes, is:

$$
e_{i}^{A}=\frac{2 a c_{i}-3 b \zeta-2 c_{i} \zeta}{6 b c_{i}},
$$

where $b<\frac{2 c_{i}(a-\zeta)}{3 \zeta}$ is required, for equilibrium emissions to be positive. Notice that $e_{i}^{A}<e_{i}^{N}$ for any level of $\zeta$.

Substituting $\left(q_{i}^{A}, e_{i}^{A}\right)$ into (6), we obtain firm $i$ 's profit:

$$
\left(\pi_{i}^{A}\right)^{\text {Taxes }}=\frac{4 a^{2} c_{i}-8 a c_{i} \zeta+\left(9 b+4 c_{i}\right) \zeta^{2}}{36 b c_{i}} .
$$

The aggregate level of emissions $E_{t}$ which serves as a benchmark for reduction of emissions is:

$$
E^{A}=e_{1}^{A}+e_{2}^{A}
$$

\subsection{Emission standards}

Under emission standards regulation and Cournot competition, the firms will maximize the following profit function:

$$
\left(\pi_{i}^{A}\right)^{\text {Standards }}=\max _{q_{i}}\left\{p(Q) q_{i}-c_{i}\left(q_{i}-e_{i}\right)^{2}\right\}
$$

subject to $e_{i} \leq \bar{e}_{i}$ where $\bar{e}_{i}$ is the emission standard established for firm $i$. Setting $e_{i}=\bar{e}_{i}$ we assume that the emission standard is equal to the amount of emission that the firm produces under taxes $\left(e_{i}^{A}\right)$. The optimal level of output for each kind of firm is given by the FOC for $q_{i}$ :

$$
p(Q)+p^{\prime}(Q) q_{i}-2 c_{i}\left(q_{i}-e_{i}^{A}\right)=0 .
$$

The third term of (12) indicates that the environmental regulation raises marginal production costs by an amount equal to the marginal abatement cost at $e_{i}=e_{i}^{A}$, which depend on the tax $\zeta$. Substituting (9) into (12) and solving the resulting term for $q_{i}$, we obtain the firm i's best response function under emission standards:

$$
q_{i}=\frac{3 a b+2 a c_{i}-3 b^{2} q_{j}-\left(3 b+2 c_{i}\right) \zeta}{6 b\left(b+c_{i}\right)} .
$$


Thus, the optimal level of output of the firm is:

$$
q_{i}^{A}=\frac{a-\zeta}{3 b},
$$

which equals the level of output that the firm will produce under tax regulation. Finally, substituting (13) and (9) into (11) we obtain the following expression for the operating profit:

$$
\left(\pi_{i}^{A}\right)^{\text {Standards }}=\frac{4 a^{2} c_{i}+4 a c_{i} \zeta-\left(9 b+8 c_{i}\right) \zeta^{2}}{36 b c_{i}} .
$$

Observe that $\left(\pi_{i}^{A}\right)^{\text {Taxes }}<\left(\pi_{i}^{A}\right)^{\text {Standards }}$ for any level of $\zeta$.

\subsection{Permits}

Under tradeable permits regulation, each firm looks for the output and the mix of abatement plus emission permits that maximize profits. Following Montero (2002 a,b) and Coria (2009), freely allocated permits and auctioned permits can be analyzed within a unique framework. Denote by $\varepsilon_{i}(>0)$ the quantity of permits received by firm $i$ and by $\beta$ the market-clearing price of permits after a total of $E^{A}$ permits have been distributed gratis by the regulator. If instead the $E^{A}$ permits are auctioned off $\varepsilon_{i}=0$, and both firms become buyers of permits ${ }^{1}$.

Under permits regulation, the firms will maximize the following function:

$$
\left(\pi_{i}^{A}\right)^{\text {Permits }}=\max _{e_{i}, q_{i}}\left\{p(Q) q_{i}-c_{i}\left(q_{i}-e_{i}\right)^{2}-\beta\left(e_{i}-\varepsilon_{i}\right)\right\} .
$$

The optimal level of emissions and production for each firm is given by the FOCs for $e_{i}$ and $q_{i}$ :

$$
\begin{gathered}
2 c_{i}\left(q_{i}-e_{i}\right)=\beta \\
p(Q)+p^{\prime}(Q) q_{i}-2 c_{i}\left(q_{i}-e_{i}\right)=0 .
\end{gathered}
$$

Eq. (15) indicates that at the optimum, each firm faces a marginal abatement cost equal to the permit price $\beta$. Combining the FOCs for $e_{i}$ and $q_{i}$, we have:

$$
p(Q)+p^{\prime}(Q) q_{i}=\beta .
$$

The term on the left-hand side of Eq. (16) is the marginal benefit of production, while the term on the right-hand side is the marginal abatement cost. At the optimum, each firm faces a benefit per unit of output equal to the permit price $\beta$.

\footnotetext{
${ }^{1}$ As remarked by Montero (2002 p. 32) the auction clearing price of permits is the same as the market-clearing price of permits because there are no income effects.
} 
The permits demand for each firm is obtained from (15):

$$
e_{i}=\frac{2 c_{i} q_{i}-\beta}{2 c_{i}},
$$

The market clearing condition requires total demand to be equal to total supply:

$$
e_{1}+e_{2}=E^{A},
$$

where $E^{A}$ is equal to the total amount of emissions that the firms will produce under taxes. The optimal level of output of the two firms can be obtained from (16). Thus:

$$
q_{i}^{* A}=\frac{a-\beta}{3 b},
$$

Substituting (19) into (17), we obtain:

$$
e_{i}^{* A}=\frac{2 a c_{i}-3 b \beta-2 c_{i} \beta}{6 b c_{i}} .
$$

Substituting (20) and (10) into (18) and solving for $\beta$, we get:

$$
\beta^{*}=\zeta .
$$

The market clearing price of permits is equal to the emission tax $\zeta$. Therefore:

$$
q_{i}^{A}=\frac{a-\zeta}{3 b},
$$

and:

$$
e_{i}^{A}=\frac{2 a c_{i}-3 b \zeta-2 c_{i} \zeta}{6 b c_{i}} .
$$

which are equal to the levels of output and emission under taxes. Substituting (21) and (22) into (14) we obtain the following expression for profits:

$$
\left(\pi_{i}^{A}\right)^{\text {Permits }}=\frac{4 a^{2} c_{i}-8 a c_{i} \zeta+\zeta\left(4 c_{i} \zeta+9 b\left(\zeta+4 c_{i} \varepsilon_{i}\right)\right)}{36 b c_{i}} .
$$

Notice that if permits are auctioned off (i.e., $\varepsilon_{i}=0$ ), the operating profit (23) is equal to the operating profits under taxes, while if permits are distributed freely (i.e., $\varepsilon_{i}>0$ ) the operating profit (23) is greater than the operating profits under taxes (since firms can gain from permits trading). Finally, note that the operating profit under auctioned permits is smaller than the operating profit under emission standards for any level of $\zeta$ (since the operating profit under auctioned profits is equal to the operating profit under taxes) while the operating profit under freely allocated permits is larger than the operating profit under emission standard for any $b>\frac{2 c_{i}(a-\zeta)}{3\left(2 c_{i} \varepsilon_{i}+\zeta\right)}$. 


\section{The regulator's problem}

In this section we analyze the behavior of the regulator and the optimal stopping problem under each instrument. Here we consider the case where the government revenues generated by pollution taxes and auctioned permits are redistributed to the firms and the consumers. In Section 5 we will examine an alternative fiscal policy decision and assume that the collected revenues are used to finance pollution abatement activities.

\subsection{The optimal stopping problem under each policy in- strument}

Using $v\left(v=T, S, P^{F r}\right.$ and $\left.P^{A u}\right)$ to denote the policy regime (i.e., taxes, emission standards, freely allocated tradeable permits and auctioned permits, respectively), in each period the regulator is supposed to decide whether to adopt the new environmental policy $v$ or to postpone it to the next period.

Like Pindyck (2000), we assume that the flow of social costs (i.e. damages) associated with the stock variable $M_{t}$ is measured by the linear function:

$$
D\left(\theta_{t}, M_{t}\right)=\theta_{t} M_{t}
$$

where $\theta_{t}$ is a variable that stochastically shifts over time to reflect the damage due to the pollutant and is assumed to follow a geometric Brownian motion:

$$
d \theta_{t}=\alpha \theta_{t} d t+\sigma \theta_{t} d z_{t}, \quad \theta_{0}=\theta
$$

for constants $\alpha<r, \sigma>0, z_{t}$ is a standard Brownian motion and $r$ denotes the risk-free rate of interest. The process $\theta_{t}$ is assumed to capture economic uncertainty over future costs and benefits of policy adoptions. For example, changes in $\theta_{t}$ might reflect the innovation of technologies that would reduce the damage from a pollutant, or a change in the society environmental sensitivity that would increase the social cost of $M_{t}$. The linearity of $D\left(\theta_{t}, M_{t}\right)$ is convenient because it makes the optimal policy independent of the stock $M_{t}$.

Let $B\left(\theta_{t}, M_{t}\right)$ denote the net benefit from emissions, i.e. the sum of consumer surplus $(C S)$ plus the total profits earned by the firms (I) plus the government revenue generated by each policy instrument $(R V)$ minus the environmental damage due to firms' production, $D$. If the regulator adopts the policy $v$, the net benefit, is:

$B_{v}^{A}\left(\theta_{t}, M_{t}\right)=C S_{t}^{A}+\left(\Pi_{t}^{A}\right)_{v}+\left(R V_{t}^{A}\right)_{v}-D^{A}\left(\theta_{t}, M_{t}\right)$, for $v=T, S, P^{F r}$ and $P^{A u}$

where $\left(\Pi^{A}\right)_{v}=\left(\pi_{1}^{A}\right)_{v}+\left(\pi_{2}^{A}\right)_{v}$ is the aggregated profit under each policy instrument. Given the demand curve, the consumer surplus $C S_{t}^{A}$ is equal to:

$$
C S^{A}=\frac{b}{2}\left(Q^{A}\right)^{2}
$$


where $Q^{A}=q_{1}^{A}+q_{2}^{A}$ is the aggregate quantity in the presence of intervention. The government revenue generated by each policy instrument is equal to:

$$
\left(R V^{A}\right)_{v}=\left\{\begin{array}{c}
\zeta E^{A} \text { if } v=T, P^{A u} \\
0 \text { if } v=S, P^{F r}
\end{array}\right.
$$

Both an emission tax and a system of auctioned permits generate government revenues (which equal the tax rate times the determined emission target under taxes), while emission standards and freely allocated permits do not generate any government revenue. The revenue from taxes and auctioned permits can be spent or redistributed to society. Here, we assume that the total tax (auction) revenue is completely redistributed to consumers and firms in a lump-sum fashion. is:

On the other hand, if the regulator never adopts the policy $v$, the net benefit

$$
B^{N}\left(\theta_{t}, M_{t}\right)=C S_{t}^{N}+\Pi_{t}^{N}-D^{N}\left(\theta_{t}, M_{t}\right)
$$

where $\Pi^{N}=\pi_{1}^{N}+\pi_{2}^{N}$ is the aggregated profit with no intervention, $C S^{N}=$ $\frac{b}{2}\left(Q^{N}\right)^{2}$ is the consumer surplus and $Q^{N}=q_{1}^{N}+q_{2}^{N}$ is the aggregate quantity in the absence of intervention. Here $R V^{N}=0$, because there is no public revenue in the absence of regulator's intervention.

Let $K\left(E^{N}-E^{A}\right)$ be the cost of permanently reducing the emission flows, which is given by:

$$
K\left(E^{N}-E^{A}\right)=h_{1}\left(E^{N}-E^{A}\right)+h_{2}\left(E^{N}-E^{A}\right)^{2},
$$

with $h_{1}, h_{2} \geq 0$. For simplicity, it is assumed that all instruments require the same gross investment cost $K\left(E^{N}-E^{A}\right)$. This cost is assumed to be completely sunk.

The objective of the regulator is to choose the optimal timing of adopting policy $v$ that would reduce emissions to $E^{A}$ such that the expected net present value function (using the discount rate $r$ ) of the difference between the net benefit $B\left(\theta_{t}, M_{t}\right)$ and the cost of policy adoption $K\left(E^{N}-E^{A}\right)$, is maximized:

$$
W_{v}(\theta, M)=\sup _{\tau_{v} \in \mathcal{T}} \mathbb{E}\left\{\int_{0}^{\infty} e^{-r t} B\left(\theta_{t}, M_{t}\right) d t-K\left(E^{N}-E^{A}\right) e^{-r \tau_{v}} \mid \mathcal{F}_{t}\right\},
$$

subject to Eq. (1) for the evolution of $M_{t}$ and Eq. (24) for the evolution of $\theta_{t}$. Here, $\mathcal{T}$ is the class of admissible implementation times conditional to the filtration generated by the stochastic process $\theta_{t}$. As usual, it is assumed that $r+\delta>\alpha$ for the integrability of the net benefit function $B\left(\theta_{t}, M_{t}\right)$.

Applying the Dixit and Pindyck (1994) methodology, we can derive the optimal timing for the four environmental policies and the values to reduce emissions 
under the four environmental policies (see the Appendix). In particular, we can compute the critical threshold $\hat{\theta}_{v}, v=T, S, P^{F r}$ and $P^{A u}$ such that it is optimal to adopt policy $v$ for $\theta>\hat{\theta}_{v}$, with:

$\hat{\theta}_{v}=\left(\frac{\phi_{1} \kappa_{1} \kappa_{2}}{r\left(E^{N}-E^{A}\right)\left(\phi_{1}-1\right)}\right)\left(\frac{b}{2}\left[\left(Q^{N}\right)^{2}-\left(Q^{A}\right)^{2}\right]+\Pi^{N}-\left(\Pi^{A}\right)_{v}-\left(R V^{A}\right)_{v}+r K\left(E^{N}-E^{A}\right)\right)$

where $\kappa_{1}=r-\alpha, \kappa_{2}=r+\delta-\alpha$ and $\phi_{1}$ is the positive solution to the standard characteristic equation. From a comparison among the critical thresholds $\hat{\theta}_{v}$ and among the welfare functions $W_{v}$, we can get the following main results:

Proposition 1 The optimal adoption thresholds under taxes, auctioned permits and emission standards are equivalent.

Proposition 2 The value of the welfare functions $W$ under taxes, auctioned permits and emission standards are equivalent.

For the following, let

$$
b^{*}=\frac{4 c_{1} c_{2}(a-\zeta)}{3\left(c_{1}\left(2 c_{2}\left(\varepsilon_{1}+\varepsilon_{2}\right)+\zeta\right)+c_{2} \zeta\right)}
$$

be the critical value of of the slope of market demand $b$ that makes the regulator indifferent between adopting emission standards and freely allocated permits. From a comparison between the thresholds $\hat{\theta}_{S}$ and $\hat{\theta}_{P F r}$ and between the welfare functions $W_{S}$ and $W_{P F r}$, we can get the following main results:

Proposition 3 The optimal adoption threshold under freely allocated permits is larger than the adoption threshold under emission standards (or auctioned permits or taxes) for $0<b<b^{*}$. The optimal adoption threshold under emission standards (or auctioned permits or taxes) is larger than the adoption threshold under freely allocated permits for $b>b^{*}$.

Proposition 4 The value of the welfare function $W$ under freely allocated permits is smaller than the value of the welfare function $W$ under emission standards (or auctioned permits or taxes) for $0<b<b^{*}$. The value of the welfare function $W$ under freely allocated permits is larger than the value of the welfare function $W$ under emission standards (or auctioned permits or taxes) for $b>b^{*}$.

Proof. of Propositions 1, 2, 3 and 4: in the Appendix.

Corollary 5 The values of the options to reduce emissions under taxes, auctioned permits and emission standards are equivalent. The value of the option to reduce emissions under freely allocated permits is smaller than the value of the option to reduce emissions under emission standards (or auctioned permits or taxes) for $0<b<b^{*}$. The value of the option to reduce emissions under freely allocated permits is larger than the value of the option to reduce emissions under emission standards (or auctioned permits or taxes) for $b>b^{*}$. 
Propositions 1 and 2 are a straightforward consequence of the following facts: $(i)$ the (aggregated) profit under auctioned permits is equal to the profit under taxes, and (ii) the (aggregated) profit under emission standards is equal to the profit under taxes plus the revenue generated by the policy instrument, as shown in the Appendix. One clearly observes this by comparing the critical thresholds and the value of the options to reduce emission under taxes, auctioned permits and emission standards.

Similarly, Propositions 3 and 4 are a straightforward consequence of the fact that the (aggregated) profit under emission standards is larger than the operating profit under freely allocated permits for $0<b<b^{*}$, while for $b>b^{*}$ the operating profits under freely allocated permit is larger than the operating profits under emission standards (see the Appendix). The comparison between emission standards (or auctioned permits or taxes) and freely allocated permits depends ultimately on the market price elasticity. If the output demand is more elastic ( $b$ smaller), then freely allocated permits offer smaller incentives than emission standards (or auctioned permits or taxes); alternatively, if it is more inelastic ( $b$ larger), then the reverse is true. Thus, Propositions 1, 2, 3 and 4 provide us with a ranking between taxes, emission standards auctioned permits and freely allocated permits in this setting, in a non equivocal way. It is found that emission standards, emission taxes and auctioned permits are more conducive to early adoption than freely allocated tradeable permits for $0<b<b^{*}$. Regulators may care about early adoption: in this case, emission standards, taxes and auctioned permits outperform freely allocated permits, i.e. they should be the preferred policy instrument. Contrarily, for $b>b^{*}$ freely allocated permits are more conducive to early adoption than emission standards, taxes and auctioned permits.

\section{The optimal stopping problem with public spend- ing}

In this section we analyze the optimal stopping problem when the government revenue generated by pollution taxes and auctioned permits are used to finance pollution abatement activities, e.g. abatement of water pollution, air pollution, and, more generally, policies that protect the natural resources. Such policies are costly and a major conviction is that public finance should play a role in meeting such requirements (see also European Commission Reports, 2009, 2010).

\subsection{Budget constraint}

Pollution taxes generate $\zeta E^{A}$ revenues. Suppose that the government decides to use these revenues to finance pollution abatement activities. Assuming a balanced budget, we have:

$$
G S=\zeta E^{A}
$$


where $G S$ denotes government spending. Under emission standard regulation, firms' emissions are limited to the quantity of emissions that the firms will produce under taxes. Hence, in this situation there are neither public revenues nor pollution abatement activities, i.e. $G S=0$.

Finally, under tradeable permits system, a total number of $E^{A}$ permits are either distributed freely or auctioned off. Hence, the government spending is equal to $G S=\zeta E^{A}$ if permits are auctioned off and is equal to $G S=0$ if permits are distributed freely.

\subsection{The pollution process and the regulator's problem with public abatement expenditures}

It is reasonable to modify the pollution dynamics in the adoption region in the following way:

$$
\begin{aligned}
d M_{t} & =\left(E^{A}-G S-\delta M_{t}\right) d t \\
& =\left(\xi^{A}-\delta M_{t}\right) d t, \text { for } t \geq \tau
\end{aligned}
$$

Under this assumption, the speed of pollution accumulation is reduced by a factor $G S$ which measures the environmental benefits associated to the government spending on pollution abatement activities. It is helpful to rewrite (2) as follows

$$
d M_{t}=\left\{\begin{array}{l}
\left(E^{N}-\delta M_{t}\right) d t \text { for } 0 \leq t<\tau_{v} \\
\left(l^{A}-\delta M_{t}\right) d t \text { for } t \geq \tau_{v},
\end{array}\right.
$$

where:

$$
l^{A}= \begin{cases}\xi^{A} & \text { if } v=T, P^{A u} \\ E^{A} & \text { if } v=S, P^{F r}\end{cases}
$$

with $\xi^{A} \equiv E^{A}-G S=(1-\zeta) E^{A}$. In such a framework there is more abatement with taxes and auctioned permits than with emission standards or freely allocated permits for $0<\zeta<1$.

Let $K\left(E^{N}-l^{A}\right)$ be the (sunk) cost of permanently reducing the emission flows, which is given by:

$$
K\left(E^{N}-l^{A}\right)=h_{1}\left(E^{N}-l^{A}\right)+h_{2}\left(E^{N}-l^{A}\right)^{2},
$$

with $h_{1}, h_{2} \geq 0$, and $l^{A}=\xi^{A}$ if $v=T, P^{A u}$ and $l^{A}=E^{A}$ if $v=S, P^{F r}$. Here the cost of permanently reducing emission flows is larger under taxes and auctioned permits than under emission standards and freely allocated tradeable permits. It is also in keeping with some empirical evidence, where emission standards and freely allocated permits are easier to be implemented and require smaller organizational and administrative costs. 
The objective of the regulator is to choose the optimal timing of adopting policy $v$ that would reduce emissions to $l^{A}$ such that the expected net present value function of the difference between the net benefit $B\left(\theta_{t}, M_{t}\right)$ and the cost of policy adoption $K\left(E^{N}-l^{A}\right)$ is maximized:

$$
W_{v}(\theta, M)=\sup _{\tau_{v} \in \mathcal{T}} \mathbb{E}\left\{\int_{0}^{\infty} e^{-r t} B\left(\theta_{t}, M_{t}\right) d t-K\left(E^{N}-l^{A}\right) e^{-r \tau_{v}} \mid \mathcal{F}_{t}\right\},
$$

where $B^{N}\left(\theta_{t}, M_{t}\right)=C S_{t}^{N}+\Pi_{t}^{N}-D^{N}\left(\theta_{t}, M_{t}\right)$ is the net benefit in the absence of intervention and $B_{v}^{A}\left(\theta_{t}, M_{t}\right)=C S_{t}^{A}+\left(\Pi_{t}^{A}\right)_{v}-D^{A}\left(\theta_{t}, M_{t}\right)$ is the net benefit in the presence of regulator's intervention. Notice that environmental revenues are not included in $B_{v}^{A}\left(\theta_{t}, M_{t}\right)$ since they are completely used to finance public abatement.

Following the same calculation as before, we can derive the optimal thresholds for each policy instrument. In particular, we can compute the critical threshold $\tilde{\theta}_{v}, v=T, S, P^{F r}$ and $P^{A u}$ such that it is optimal to adopt policy $v$ for $\theta>\tilde{\theta}_{v}$, with:

$\tilde{\theta}_{v}=\left(\frac{\phi_{1} \kappa_{1} \kappa_{2}}{r\left(E^{N}-l^{A}\right)\left(\phi_{1}-1\right)}\right)\left(\frac{b}{2}\left[\left(Q^{N}\right)^{2}-\left(Q^{A}\right)^{2}\right]+\Pi^{N}-\left(\Pi^{A}\right)_{v}+r K\left(E^{N}-l^{A}\right)\right)$,

for $l^{A}=\xi^{A}$ if $v=T$ and $P^{A u}$ and $l^{A}=E^{A}$ if $v=S$ and $P^{F r}$. From a comparison between the thresholds $\tilde{\theta}_{T}$ and $\tilde{\theta}_{P A u}$ and between the welfare functions $W_{T}$ and $W_{P^{A u}}$, we can get the following main results:

Proposition 6 Assuming that the collected revenues are used to finance pollution abatement activities: (i) the optimal adoption threshold under taxes is the same as the optimal adoption threshold under auctioned permits; (ii) the value of the welfare function $W$ under taxes is the same as the value of the welfare function $W$ under auctioned permits.

Moreover, from a comparison between the thresholds $\tilde{\theta}_{S}$ and $\tilde{\theta}_{P F r}$ and between the welfare functions $W_{T}$ and $W_{P^{A u}}$, we can get the following main results:

Proposition 7 Assuming that the collected revenues are used to finance pollution abatement activities: (i) the optimal adoption threshold under freely allocated permits is larger than the adoption threshold emission standards for $0<b<b^{*}$; (ii) the optimal adoption threshold under emission standards is larger than the adoption threshold under freely allocated permits for $b>b^{*}$.

Proposition 8 Assuming that the collected revenues are used to finance pollution abatement activities: (i) the value of the welfare function $W$ under freely allocated permits is smaller than the value of the welfare function $W$ under emission standards for $0<b<b^{*}$; (ii) the value of the welfare function $W$ under 
emission standards is smaller than the value of the welfare function $W$ under freely allocated permits for for $b>b^{*}$.

Proof. of Propositions 6, 7 and 8: in the Appendix.

Unfortunately, we cannot compare the critical threshold under taxes and auctioned permits with the critical thresholds under emission standards and freely allocated permits, in our theoretical model. The reason is that there is more abatement with taxes and auctioned permits than with emission standards or freely allocated permits and hence the levels of emissions are different under the different policy instruments. However, numerical simulations allow us to compare the critical thresholds under taxes, emission standards and permits. This will help us to shed light on the possible rankings of the policy instruments under different specifications of the parameter values. We find that the critical threshold under taxes and auctioned permits is always larger than the critical threshold under emissions standards and auctioned permits. The reason is that taxes and auctioned permits require higher costs of implementation and therefore the stopping value associated with emission level $\xi^{A}$ is lower than the stopping value associated with the emission $E^{A}$. When we compare the stopping values with the continuation values it results that at the optimal adoption time the critical thresholds under emission standards and freely allocated permits are lower than the critical thresholds under taxes and auctioned permits. Hence, emission standards and freely allocated permits are preferred to taxes and auctioned permits if the regulator aims at speeding up the adoption of pollution reducing policies. Moreover, comparing the critical thresholds under emission standards and freely allocated permits we find that emission standards are preferred to freely allocated permits when the output demand is more elastic, while freely allocated permits are preferred if the output demand is more inelastic. This result is in contrast with Coria (2009) where a different ranking is found. In particular, Coria (2009) shows that if the regulator wants to speed up technological diffusion (i.e. firms adopting pollution reducing technology) auctioned permits are preferred to freely allocated permits and taxes when the output demand is more elastic. Her model, however, considers a different case where a policy is adjusted in response to the availability of a new technology.

\section{Simulation results}

In this section we provide some numerical applications and sensitivity analysis of the optimal thresholds under the alternative environmental policies for the reduction of emissions. The simulations are implemented with Mathematica Programming. We assume that in the base case: $\alpha=0.01$ (drift-rate of economic uncertainty), $r=0.04$ (risk-free interest rate), $\sigma=0.2$ (volatility of economic uncertainty), $\delta=0.02$ (natural rate of dispersion of pollution), $k_{1}=100$ (proportional cost), $k_{2}=100$ (adjustment cost), $a=5$ (average market size), $b=1$ (slope of the market demand), $c_{1}=4$ (index of cost for firm 1 ), 
$c_{2}=3$ (index of cost for firm 2), $\varepsilon_{1}=3$ (quantity of emissions permits received by firm 1 ), $\varepsilon_{2}=2$ (quantity of emissions permits received by firm 2 ), $\zeta=0.2$ (emission tax). The case $b=1$ corresponds to an inelastic demand case.

Figure 1 shows the relation between the critical threshold $\tilde{\theta}_{v}, v=T, S, P^{F r}$ and $P^{A u}$ and the volatility $\sigma$. The dashed curve refers to the critical threshold under taxes, the solid curve to emission standards and the dotted curve to freely allocated tradeable permits. We recall that the critical threshold under taxes coincides with the critical threshold under auctioned permits. We consider values of the volatility $\sigma$ ranging from 0 to 1 . As in Pindyck (2000), the critical thresholds are upward sloping with respect to $\sigma$. The reason is that an increase of economic uncertainty over future payoffs from reduced emissions increases the value of waiting and raises the critical threshold $\tilde{\theta}_{v}$. The simulation provides us with a ranking between taxes, emission standards, freely allocated tradeable permits and auctioned permits (in terms of their adoption lag) when $\sigma$ increases. We observe that the critical threshold under taxes and auctioned permits is larger than the critical thresholds under emissions standards and auctioned permits; moreover, it is found that the critical threshold under freely allocated permits is lower than the critical thresholds under emissions standards, taxes and auctioned permits. That means that freely allocated permits are more conducive to early adoption than emission taxes, emission standards and auctioned permits in this base case.

Figure 2 shows the relation between the critical threshold $\tilde{\theta}_{v}, v=T, S, P^{F r}$ and $P^{A u}$ and and the emission tax rate $\zeta$. The dashed curve illustrates the sensitivity of the critical threshold under taxes, the solid curve under emission standards and the dotted curve under freely allocated tradeable permits. We consider values of the emission tax rate $\zeta$ ranging from 0 to 1 . The critical thresholds are upward sloping with respect to $\zeta$. The reason is that a higher $\zeta$ reduces firm's profits and thus necessitates a higher $\theta$ for the investment in reduced emissions to take place. The intuition is as follows. The optimal implementation time is defined as that level of $\theta$ at which the continuation and the termination values are equal. Evaluating both values at $\tilde{\theta}_{v}$ and increasing the level of stringency of environmental policy, decreases both the continuation and the termination values. Indeed, a larger $\zeta$ would reduce the level of emission flow and reduce the social cost of environmental damage. Moreover, higher levels of environmental stringency render the firm's economic activity less profitable, and hence reduce the value of the option to implement the environmental policy (which would reduce social damage) in the future; overall, the effect on firm's profits seems to dominate. That means that when faced with a more stringent environmental policy, the continuation value associated with the emissions level $E^{N}$ is larger than its termination value with emissions level $l^{A}$, and hence the regulator will decide to wait longer for adopting the new environmental policy $v$.

The result that the more stringent the policy, the more firms would delay the adoption of lower emission policies, was also highlighted in Van Soest (2005), however, using a different model with a different objective function. Also Agliardi and Sereno (2011) obtain the same sensitivity results with re- 
spect to the stringency of environmental policy, although permits and public expenditures are not taken into account.

The numerical simulation provides us with a ranking between taxes, emission standards and permits. It is found that the critical threshold under taxes and auctioned permits is larger than the critical thresholds under emissions standards and freely allocated permits. Moreover, it is found that the critical threshold under freely allocated permits is lower than the critical thresholds under taxes, emissions standards and auctioned permits. As in the previous case, freely allocated permits are more conducive to early adoption than emission taxes, emission standards and auctioned permits.

Figure 3 shows the relation between the critical threshold $\tilde{\theta}_{v}, v=T, S, P^{F r}$ and $P^{A u}$ and the slope of the market demand $b$. The dashed curve refers to the critical threshold under taxes and auctioned permits, the solid curve to emission standards and the dotted curve to freely allocated tradeable permits. We consider values of $b$ ranging from 0.1 (elastic output demand case) to 2 (inelastic output demand case). The critical thresholds are downward sloping with respect to $b$. The reason is that a higher $b$ would reduce the level of emission flow and reduce the social cost of environmental damage and thus necessitates a lower $\theta$ for the investment in reduced emissions to take place. The intuition is as follows. In the Cournot game the level of output depends inversely on the price elasticity. As the output demand is more inelastic the level of emissions is lower and the firm's economic activity is less profitable. Also the option to implement the environmental policy (which would reduce social damage) in the future is less valuable. That means that when faced with a more inelastic output demand, the continuation value associated with the emissions level $E^{N}$ is lower than its termination value with emissions level $l^{A}$, and hence the regulator will decide to speed up the adoption of the new environmental policy $v$.

The numerical simulation provides us with a ranking between taxes, emission standards, freely allocated tradeable permits and auctioned permits, in terms of their adoption lag, when $b$ increases. It is found that (i) the critical threshold under taxes and auctioned permits is larger than the critical thresholds under emissions standards and freely allocated permits. (ii) the critical threshold under freely allocated permits is larger than the critical threshold under emission standards for values of $b$ ranging between 0 and about 0.63 , while the critical threshold under emission standards is larger than the critical threshold under freely allocated permits for values of $b$ greater than about 0.63 . Thus, the regulator is indifferent between adopting emission standards and freely allocated permits when $b \cong 0.63$. The regulator will prefer emission standards to freely allocated permits when the value of $b$ ranges between 0 and (about) 0.63 . And finally the regulator will prefer freely allocated permits to emission standards when the value of $b$ is greater than (about) 0.63 .

Finally, Figure 4 shows the relation between the critical threshold $\tilde{\theta}_{v}, v=$ $T, S, P^{F r}$ and $P^{A u}$ and the average market size $a$. The dashed curve refers to the critical threshold under taxes and auctioned permits, the solid curve to emission standards and, finally, the dotted curve to freely allocated tradeable permits. We consider values of $a$ ranging from 1 to 15 . It is found that freely allocated 
permits are more conducive to early adoptions than taxes, emission standards and auctioned permits for values of $a$ ranging between 0 and 7.7875 , while for values of $a$ greater than 7.7875 emission standards are more conducive to early adoption than taxes, emission standards and auctioned permits.

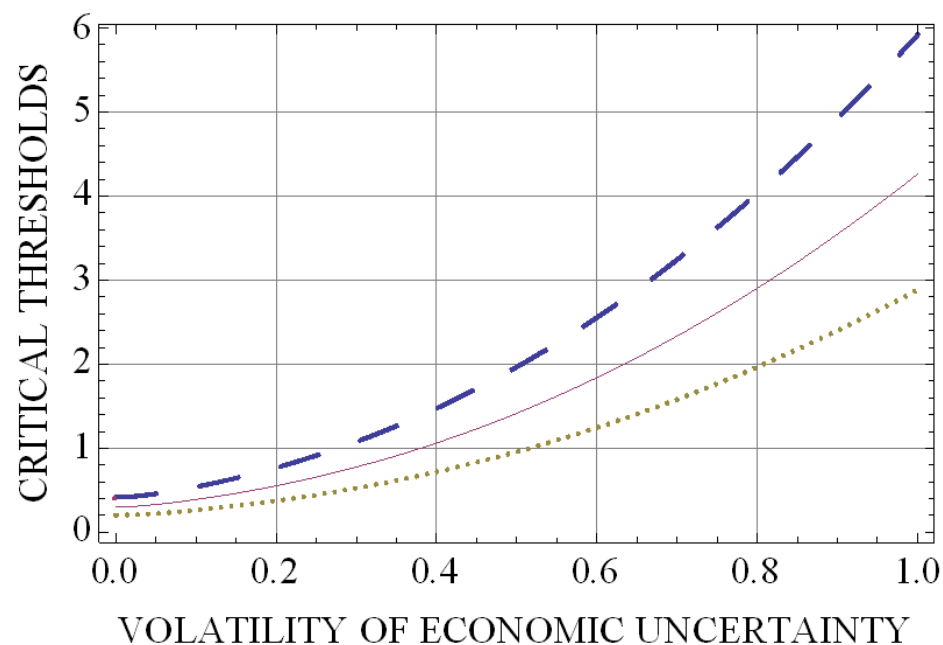

FIGURE 1: Relation between the critical threshold $\tilde{\theta}_{T}$ and $\tilde{\theta}_{P A u}$ and the volatility of economic uncertainty $\sigma$ (dashed curve). Relation between the critical thresholds $\tilde{\theta}_{S}$ and the volatility of economic uncertainty $\sigma$ (solid curve). Relation between the critical thresholds $\tilde{\theta}_{P F r}$ and the volatility of economic uncertainty $\sigma$ (dotted curve). 


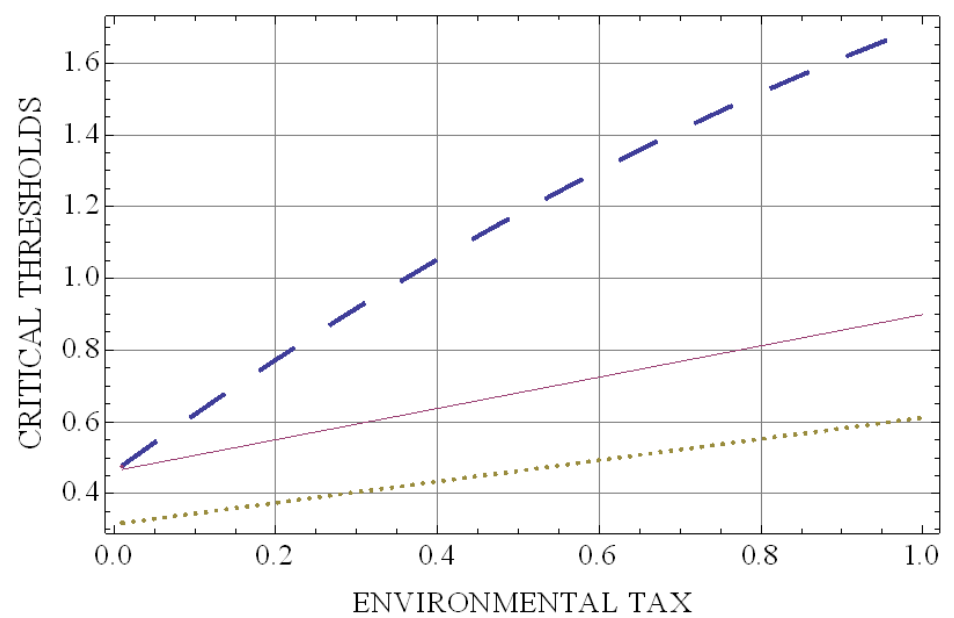

FIGURE 2: Relation between the critical threshold $\tilde{\theta}_{T}$ and $\tilde{\theta}_{P A u}$ and the environmental tax $\zeta$ (dashed curve). Relation between the critical thresholds $\tilde{\theta}_{S}$ and the environmental tax $\zeta$ (solid curve). Relation between the critical thresholds $\tilde{\theta}_{P F r}$ and the environmental tax $\zeta$ (dotted curve).

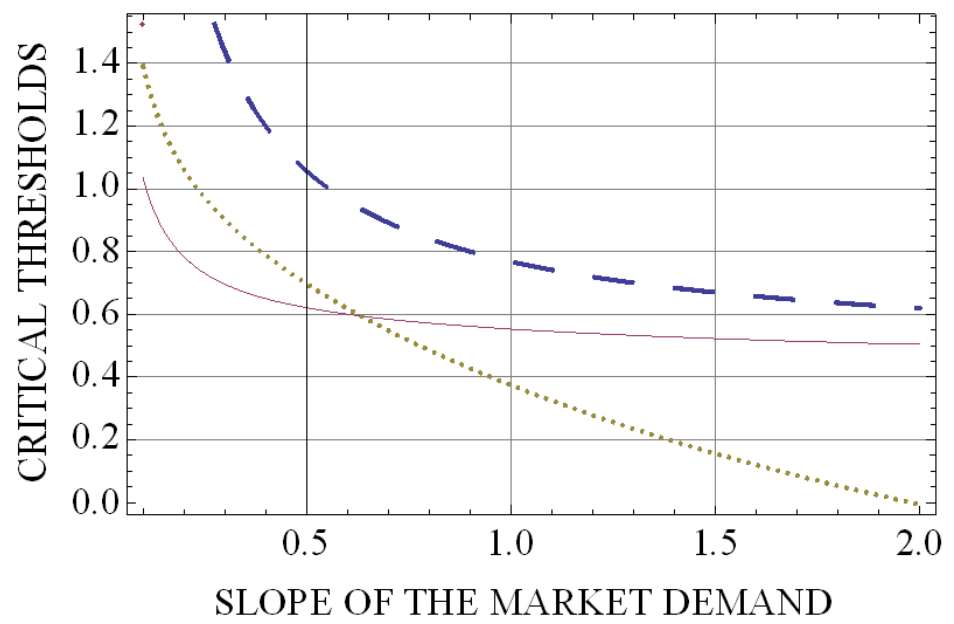

FIGURE 3: Relation between the critical threshold $\tilde{\theta}_{T}$ and $\tilde{\theta}_{P^{A u}}$ and the slope of the market demand $b$ (dashed curve). Relation between the critical thresholds $\tilde{\theta}_{S}$ and the slope of the market demand $b$ (solid curve). Relation between the critical thresholds $\tilde{\theta}_{P F r}$ and the slope of the market demand $b$ (dotted curve). 


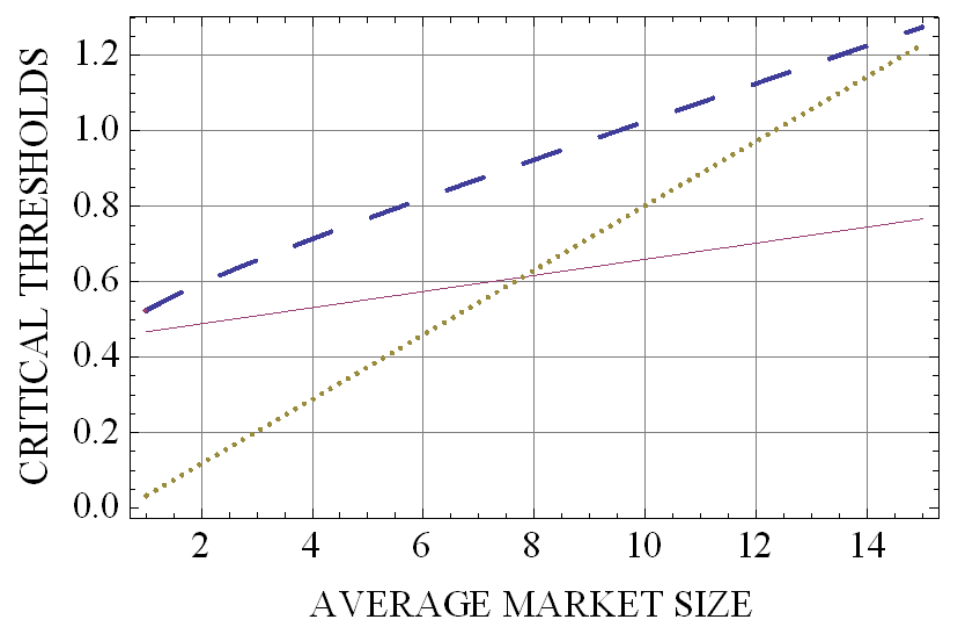

FIGURE 4: Relation between the critical threshold $\tilde{\theta}_{T}$ and $\tilde{\theta}_{P^{A u}}$ and the average market size $a$ (dashed curve). Relation between the critical thresholds $\tilde{\theta}_{S}$ and the average market size $a$ (solid curve). Relation between the critical thresholds $\tilde{\theta}_{P F r}$ and the average market size $a$ (dotted curve).

\section{Conclusion}

This paper is about the optimal timing of a new environmental policy in a framework where production causes pollution, economic volatility is the main source of uncertainty, competing firms are regulated by taxes, emission standards, auctioned permits or freely allocated permits and the government is concerned with the finance requirements of the environmental protection. In particular, two possible fiscal policy decisions are considered: either, the government revenues generated by pollution taxes and auctioned permits are redistributed to the firms and the consumers, or the collected revenues are used to finance pollution abatement activities.

Our main results concern the rankings of the alternative policy options in terms of their adoption lag and social welfare. We show that when the output demand is elastic emission standards are preferred to freely allocated permits. Alternatively, if demand is inelastic, freely allocated permits provide more incentives than taxes, emission standards and auctioned permits. Taxes and auctioned permits are always equivalent in terms of their adoption lag and social 
welfare and also equivalent to emission standards when the regulator redistributes revenues.

Our paper contributes to the recent debate in the literature by discussing the impact of these alternative policy instruments on the optimal timing of emission reductions. Environmental protection and the timing of policy intervention have become a priority and a challenge for many governments indeed. In our model there is an unambiguous ranking of these policy instruments in terms of the adoption lags: if regulators wish to speed up the implementation of technologies reducing pollution emissions, then they may prefer standards to taxes or permits if demand is rather elastic. This result is robust to the two fiscal policies adopted and to various relevant parameters. Therefore, our sensitivity analysis provides a clue to regulators who are faced with environmental issues where economic costs and benefits cannot be forecasted and a lot of scenarios can be considered. An interesting extension is to examine the effects of asymmetric information among actors in the economy, for example, the effects of signaling on environmental policies where each firm privately knows whether its technology is clean or not, while third parties (i.e., the regulator) have only a subjective perception about it. We leave such issue for future research.

\section{References}

[1] Agliardi, E., Sereno, L., 2011. The effects of environmental taxes and quotas on the optimal timing of emission reductions under Choquet-Brownian uncertainty. Economic Modelling, 28, 2793-2802.

[2] Balikcioglu, M., Fackler, P.L. , Pindyck, R.S., 2011, Solving optimal timing problems in environmental economics, Resource and Energy Economics, 33 (3), 761-768.

[3] Conrad, J.M., 1997. Global warming: when to bite the bullet. Land Economics, 73, 164-173.

[4] Conrad, J.M., 2000. Wilderness: options to preserve, extract or develop. Resource and Energy Economics, 22, 205-219.

[5] Coria, J., 2009. Taxes, Permits and the diffusion of a new technology. Resource and Energy Economics, 31, 249-271.

[6] Dixit, A.K., Pindyck, R.S., 1994. Investment Under Uncertainty. Princeton University Press, Princeton.

[7] Insley, M., 2003. On the option to invest in pollution control under a regime of tradable emissions allowances. Canadian Journal of Economics, 36, 860883.

[8] Montero, J.P., 2002a. Market structure and environmental innovation. Journal of Applied Economics 5 (2), 293-325. 
[9] Montero, J.P., 2002b. Permits, standards, and technology innovation. Journal of Environmental Economics and Management 44, 23-44.

[10] Nishide, K., Ohyama, A., 2009. Using real options theory to a country's environmental policy: considering the economic size and growth. Operational Research: An International Journal, 9, 229-250.

[11] Ohyama, A., Tsujimura, M., 2006. Political measures for strategic environmental policy with external effects. Environmental and Resource Economics, 35, 109-135.

[12] Pindyck, R.S., 2000. Irreversibilities and the timing of environmental policy. Resource and Energy Economics, 22, 223-259.

[13] Pindyck, R.S., 2002. Optimal timing problems in environmental economics. Journal of Economic Dynamics and Control, 26, 1677-1697.

[14] Saphores, J.D.M., Carr, P., 2000. Real options and the timing of implementation of emission limits under ecological uncertainty. In: Brennan, M.J., Trigeorgis, L. (Eds.), Project Flexibility, Agency and Competition. New Developments in the Theory and Applications of Real Options. pp. $254-271$.

[15] Saltari, E., \& Travaglini, G., 2011. The effects of environmental policies on the abatement investment decisions of a green firm. Resource and Energy Economics, 33(3), 666-685

[16] Xepapadeas, A., 2001. Environmental Policy and Firm Behavior: Abatement Investment and Location Decisions under Uncertainty and Irreversibility in: Behavioral and Distributional Effects of Environmental Policy.

[17] Van Soest, D., 2005. The impact of environmental policy instruments on the timing of adoption of energy-saving technologies. Resource and Energy Economics, 27, 235-247.

[18] Wirl, F., 2006. Consequences of irreversibilities on optimal intertemporal CO2 emission Policies Under Uncertainty. Resource and Energy Economics, $28,105-123$.

\section{Appendix A}

Derivation of the critical threshold $\hat{\theta}_{v}, T, S, P^{A u}$ and $P^{F r}$

In this Appendix we derive the optimal timing for the environmental policy $v$. Let $W_{v}^{N}=W_{v}^{N}(\theta, M)$ denote the value function for the "no-adopt" region 
$0 \leq t<\tau_{v}$, in which $E_{t}=E^{N}$. The corresponding Hamilton-Jacobi-Bellman equation is:

$$
r W_{v}^{N}=B^{N}(\theta, M)+\left(E^{N}-\delta M\right) \frac{\partial W_{v}^{N}}{\partial M}+\alpha \theta \frac{\partial W_{v}^{N}}{\partial \theta}+\frac{1}{2} \sigma^{2} \theta^{2} \frac{\partial^{2} W_{v}^{N}}{\partial \theta^{2}} .
$$

It has the following general solution:

$$
W_{v}^{N}(\theta, M)=\Phi_{1, v} \theta^{\phi_{1}}+\Phi_{2, v} \theta^{\phi_{2}}+\left[\frac{b\left(Q^{N}\right)^{2}}{2 r}+\frac{\Pi^{N}}{r}-\frac{\theta M}{\kappa_{2}}-\frac{\theta E^{N}}{\kappa_{1} \kappa_{2}}\right]
$$

where $\Phi_{1, v}$ and $\Phi_{2, v}$ are unknowns to be determined, $\kappa_{1}=r-\alpha$ and $\kappa_{2}=$ $r+\delta-\alpha$. Here, $\phi_{1}$ and $\phi_{2}$ are the solution to the following characteristic equation:

$$
\frac{1}{2} \sigma^{2} \phi(\phi-1)+\phi \alpha-r=0
$$

and are given by:

$$
\begin{aligned}
& \phi_{1}=\frac{1}{2}-\frac{\alpha}{\sigma^{2}}+\sqrt{\left(\frac{1}{2}-\frac{\alpha}{\sigma^{2}}\right)^{2}+\frac{2 r}{\sigma^{2}}}>1 \\
& \phi_{2}=\frac{1}{2}-\frac{\alpha}{\sigma^{2}}-\sqrt{\left(\frac{1}{2}-\frac{\alpha}{\sigma^{2}}\right)^{2}+\frac{2 r}{\sigma^{2}}}<0 .
\end{aligned}
$$

The term between the squared parentheses in (26) is a particular solution, which captures the expected net benefit from emissions in the case the environmental regulator has not adopted the policy and is calculated as:

$$
\begin{gathered}
\mathbb{E}\left\{\int_{0}^{\infty} e^{-r t} B^{N}\left(\theta_{t}, M_{t}\right) d t\right\}= \\
=\int_{0}^{\infty} e^{-r t}\left(C S^{N}+\Pi^{N}\right) d t-\int_{0}^{\infty} e^{-r t} \theta e^{\alpha t}\left[\frac{E^{N}}{\delta}+\left(M-\frac{E^{N}}{\delta}\right) e^{-\delta t}\right] d t \\
=\frac{b\left(Q^{N}\right)^{2}}{2 r}+\frac{\Pi^{N}}{r}-\frac{\theta M}{\kappa_{2}}-\frac{\theta E^{N}}{\kappa_{1} \kappa_{2}},
\end{gathered}
$$

where $E^{N}$ is given by (5). Therefore, the parenthesis in (26) represents the fundamental term and the exponential terms account for the perpetual American option value.

Next, let $W_{v}^{A}(\theta, M)$ denote the value function for the adopt region $t \geq \tau_{v}$, in which $\left(R V^{A}\right)_{v}=\zeta E^{A}$ if $v=T, P^{A u}$ and $\left(R V^{A}\right)_{v}=0$ if $v=S, P^{F r}$. Since we consider environmental policies which involve a one-time reduction in $E_{t}$, 
there is no option term after pollutant emissions have been reduced to $E^{A}$. So in this case the solution to the Hamilton-Jacobi-Bellman equation is given by its particular solution which captures the regulator's expectation about net benefit from abated emissions under the policy instrument $v$ and is calculated as follows:

$$
\begin{aligned}
W_{v}^{A}(\theta, M)= & \mathbb{E}\left\{\int_{0}^{\infty} e^{-r t} B_{v}^{A}\left(\theta_{t}, M_{t}\right) d t\right\} \\
= & \int_{0}^{\infty} e^{-r t}\left[C S^{A}+\left(\Pi^{A}\right)_{v}+\left(R V^{A}\right)_{v}\right] d t \\
& -\int_{0}^{\infty} e^{-r t} \theta e^{\alpha t}\left[\frac{E^{A}}{\delta}+\left(M-\frac{E^{A}}{\delta}\right) e^{-\delta t}\right] d t \\
= & \frac{b\left(Q^{A}\right)^{2}}{2 r}+\frac{\left(\Pi^{A}\right)_{v}}{r}+\frac{\zeta E^{A}}{r}-\frac{\theta M}{\kappa_{2}}-\frac{\theta E^{A}}{\kappa_{1} \kappa_{2}} .
\end{aligned}
$$

We know that the solutions for $W_{v}^{N}(\theta, M)$ and $W_{v}^{A}(\theta, M)$ must satisfy the following set of boundary conditions (see Pindyck 2000):

$$
\begin{gathered}
W_{v}^{N}(0, M)=0, \\
W_{v}^{A}(0, M)=0, \\
W_{v}^{N}\left(\hat{\theta}_{v}, M\right)=W_{v}^{A}\left(\hat{\theta}_{v}, M\right)-K\left(E^{N}-E^{A}\right),
\end{gathered}
$$

and:

$$
\frac{\partial W_{v}^{N}\left(\hat{\theta}_{v}, M\right)}{\partial \theta}=\frac{\partial W_{v}^{A}\left(\hat{\theta}_{v}, M\right)}{\partial \theta}
$$

Here, $\hat{\theta}_{v}$ is a free boundary, which must be found as part of the solution, and which separates the adopt from the no-adopt regions. It is also the solution to the stopping problem (25):

$$
\tau_{v}=\inf \left\{t>0, \theta \geq \hat{\theta}_{v}\right\}
$$

The policy $v$ should be adopted the first time the process $\theta_{t}$ crosses the threshold $\hat{\theta}_{v}$ from below. Boundary conditions $(27)$ and (28) reflect the fact that if $\theta_{t}$ is ever zero, it will remain at zero thereafter. Conditions (29) and (30) are the value matching and the smooth-pasting conditions, respectively. Conditions (27) and (28) imply:

$$
W_{v}^{N}(0, M)=\frac{b\left(Q^{N}\right)^{2}}{2 r}+\frac{\Pi^{N}}{r}
$$

and

$$
W_{v}^{A}(0, M)=\frac{b\left(Q^{A}\right)^{2}}{2 r}+\frac{\left(\Pi^{A}\right)_{v}}{r}+\frac{\left(R V^{A}\right)_{v}}{r}
$$


Accordingly, we disregard the negative root in order to prevent the value from becoming infinitely large when $\theta_{t}$ tends to 0 ; thus, we set $\Phi_{2, v}=0$ (see Dixit and Pindyck 1994). So (13) becomes:

$$
W_{v}^{N}(\theta, M)=\Phi_{1, v} \theta^{\phi_{1}}+\frac{b\left(Q^{N}\right)^{2}}{2 r}+\frac{\Pi^{N}}{r}-\frac{\theta M}{\kappa_{2}}-\frac{\theta E^{N}}{\kappa_{1} \kappa_{2}}
$$

The first term on the right-hand side of Eq. (31) is the value of the option to adopt policy $v$ and reduce emissions to $E^{A}$, while the remaining terms represent the regulator's expectation about net benefit from emissions $B^{N}\left(\theta_{t}, M_{t}\right)$.

The value matching condition (29) can be rearranged in the following manner:

$\Phi_{1, v}\left(\hat{\theta}_{v}\right)^{\phi_{1}}=\frac{\hat{\theta}_{v}\left(E^{N}-E^{A}\right)}{\kappa_{1} \kappa_{2}}-\frac{b\left[\left(Q^{N}\right)^{2}-\left(Q^{A}\right)^{2}\right]}{2 r}-\frac{\Pi^{N}-\left(\Pi^{A}\right)_{v}-\left(R V^{A}\right)_{v}}{r}-K\left(E^{N}-E^{A}\right)$.

The smooth-pasting condition (30) yields:

$$
\Phi_{1, v}=\frac{1}{\phi_{1}\left(\hat{\theta}_{v}\right)^{\phi_{1}-1}}\left(\frac{E^{N}-E^{A}}{\kappa_{1} \kappa_{2}}\right)
$$

Plugging (33) into (32), we get:

$\hat{\theta}_{k}=\left(\frac{\phi_{1} \kappa_{1} \kappa_{2}}{\left(E^{N}-E^{A}\right)\left(\phi_{1}-1\right)}\right)\left(\frac{b\left[\left(Q^{N}\right)^{2}-\left(Q^{A}\right)^{2}\right]}{2 r}+\frac{\Pi^{N}-\left(\Pi^{A}\right)^{k}-\left(R V^{A}\right)^{k}}{r}+K\left(E^{N}-E^{A}\right)\right)$.

Finally, substituting (34) into (33), we get:

$\Phi_{1, v}=\left(\frac{E^{N}-E^{A}}{\phi_{1} \kappa_{1} \kappa_{2}}\right)^{\phi_{1}}\left(\frac{2 r\left(\phi_{1}-1\right)}{b\left[\left(Q^{N}\right)^{2}-\left(Q^{A}\right)^{2}\right]+2\left[\Pi^{N}-\left(\Pi^{A}\right)_{v}-\left(R V^{A}\right)_{v}\right]+2 r K\left(E^{N}-E^{A}\right)}\right)^{\phi_{1}-1}$.

\section{Proof of Proposition 1}

We want to show that the optimal adoption thresholds under taxes, auctioned permits and emission standards are equivalent. First we show that $\hat{\theta}_{T}=$ 
$\hat{\theta}_{S}:$

$$
\begin{aligned}
& \left(\frac{\phi_{1} \kappa_{1} \kappa_{2}}{\left(E^{N}-E^{A}\right)\left(\phi_{1}-1\right)}\right)\left(\frac{b\left[\left(Q^{N}\right)^{2}-\left(Q^{A}\right)^{2}\right]}{2 r}+\frac{\Pi^{N}-\left(\Pi^{A}\right)_{T}-\zeta E^{A}}{r}+K\left(E^{N}-E^{A}\right)\right) \\
= & \left(\frac{\phi_{1} \kappa_{1} \kappa_{2}}{\left(E^{N}-E^{A}\right)\left(\phi_{1}-1\right)}\right)\left(\frac{b\left[\left(Q^{N}\right)^{2}-\left(Q^{A}\right)^{2}\right]}{2 r}+\frac{\Pi^{N}-\left(\Pi^{A}\right)_{S}}{r}+K\left(E^{N}-E^{A}\right)\right) .
\end{aligned}
$$

By simplifying the above equation yields:

$$
\left(\Pi^{A}\right)_{T}+\zeta E^{A}=\left(\Pi^{A}\right)_{S} .
$$

Substituting the expressions for the target and profits we obtain:

$$
\begin{aligned}
& \frac{4 a^{2} c_{1}-8 a c_{1} \zeta+\left(9 b+4 c_{1}\right) \zeta^{2}}{36 b c_{1}}+\frac{4 a^{2} c_{2}-8 a c_{2} \zeta+\left(9 b+4 c_{2}\right) \zeta^{2}}{36 b c_{2}}+ \\
& \zeta\left(\frac{2 a c_{1}-3 b \zeta-2 c_{1} \zeta}{6 b c_{1}}+\frac{2 a c_{2}-3 b \zeta-2 c_{2} \zeta}{6 b c_{2}}\right) \\
= & \frac{4 a^{2} c_{1}+4 a c_{1} \zeta-\left(9 b+8 c_{1}\right) \zeta^{2}}{36 b c_{1}}+\frac{4 a^{2} c_{2}+4 a c_{2} \zeta-\left(9 b+8 c_{2}\right) \zeta^{2}}{36 b c_{2}} .
\end{aligned}
$$

Equation (35) gives zero. Thus, the critical thresholds under taxes and under emission standards are equivalent. In the same way, we can show that $\hat{\theta}_{S}=\hat{\theta}_{P^{A u}}$. Since the profits under auctioned permits and under emission taxes are equivalent, repeating the same calculations as before yields the result in Proposition 1.

\section{Proof of Proposition 2}

In order to prove Proposition 2 we rewrite $\Phi_{1, T}$ and $\Phi_{1, S}$, as follows:

$$
\begin{aligned}
\Phi_{1, T} & =\left(\frac{E^{N}-E^{A}}{\phi_{1} \kappa_{1} \kappa_{2}}\right)^{\phi_{1}}\left(\frac{2 r\left(\phi_{1}-1\right)}{b\left[\left(Q^{N}\right)^{2}-\left(Q^{A}\right)^{2}\right]+2\left[\Pi^{N}-\left(\Pi^{A}\right)_{T}-\zeta E^{A}\right]+2 r K\left(E^{N}-E^{A}\right)}\right)^{\phi_{1}-1} \\
\Phi_{1, S} & =\left(\frac{E^{N}-E^{A}}{\phi_{1} \kappa_{1} \kappa_{2}}\right)^{\phi_{1}}\left(\frac{2 r\left(\phi_{1}-1\right)}{b\left[\left(Q^{N}\right)^{2}-\left(Q^{A}\right)^{2}\right]+2\left[\Pi^{N}-\left(\Pi^{A}\right)_{S}\right]+2 r K\left(E^{N}-E^{A}\right)}\right)^{\phi_{1}-1} .
\end{aligned}
$$

It is easy to show that $\Phi_{1, T}$ equals $\Phi_{1, S}$. Let us consider the exponential term in (31) which accounts for the perpetual American option value. Then, substituting the expressions for $\Phi_{1, T}$ and $\Phi_{1, S}$ into the option term and comparing the two values, we find that the value of the option to reduce emissions under taxes is equal to the value of the option to reduce emission under emission 
standards. It should be noted that the objective function $W$ (as of $t=0$ ) should not be interpreted as the option value alone but as the social welfare function that includes the value arising from the welfare prior to the environmental policy adoption (capturing the profits earned by the non adopting firms plus the consumer surplus minus the social damage with no adoption) plus the option to implement an environmental policy (which would reduce social damage at a cost $\left.K\left(E^{N}-E^{A}\right)\right)$. By comparing the two value functions it results that the value of the welfare function $W$ under taxes is equal to the value of the welfare function under emission standards. Repeating the same reasoning it is easy to show that the value of the welfare function $W$ under emission standards is equivalent to the value of the welfare function $W$ under auctioned permits. The result in Proposition 2 follows.

\section{Proof of Proposition 3}

We want to show that the optimal adoption threshold under freely allocated permits is larger than the adoption thresholds under emission standards for $0<b<b^{*}$. Thus:

$$
\begin{aligned}
& \left(\frac{\phi_{1} \kappa_{1} \kappa_{2}}{\left(E^{N}-E^{A}\right)\left(\phi_{1}-1\right)}\right)\left(\frac{b\left[\left(Q^{N}\right)^{2}-\left(Q^{A}\right)^{2}\right]}{2 r}+\frac{\Pi^{N}-\left(\Pi^{A}\right)_{P^{F r}}}{r}+K\left(E^{N}-E^{A}\right)\right) \\
= & \left(\frac{\phi_{1} \kappa_{1} \kappa_{2}}{\left(E^{N}-E^{A}\right)\left(\phi_{1}-1\right)}\right)\left(\frac{b\left[\left(Q^{N}\right)^{2}-\left(Q^{A}\right)^{2}\right]}{2 r}+\frac{\Pi^{N}-\left(\Pi^{A}\right)_{S}}{r}+K\left(E^{N}-E^{A}\right)\right) .
\end{aligned}
$$

By simplifying the expression above we get:

$$
\left(\Pi^{A}\right)_{P^{F r}}<\left(\Pi^{A}\right)_{S} .
$$

that is:

$$
\begin{aligned}
& \frac{4 a^{2} c_{1}-8 a c_{1} \zeta+\zeta\left(4 c_{1} \zeta+9 b\left(\zeta+4 c_{1} \varepsilon_{2}\right)\right)}{36 b c_{1}} \\
+ & \frac{4 a^{2} c_{2}-8 a c_{2} \zeta+\zeta\left(4 c_{2} \zeta+9 b\left(\zeta+4 c_{2} \varepsilon_{2}\right)\right)}{36 b c_{2}} \\
< & \frac{4 a^{2} c_{1}+4 a c_{1} \zeta-\left(9 b+8 c_{1}\right) \zeta^{2}}{36 b c_{1}}+\frac{4 a^{2} c_{2}+4 a c_{2} \zeta-\left(9 b+8 c_{2}\right) \zeta^{2}}{36 b c_{2}} .
\end{aligned}
$$

Straightforward calculations yields:

$$
b<\frac{4 c_{1} c_{2}(a-\zeta)}{3\left(c_{1}\left(2 c_{2}\left(\varepsilon_{1}+\varepsilon_{2}\right)+\zeta\right)+c_{2} \zeta\right)} .
$$

where $\frac{4 c_{1} c_{2}(a-\zeta)}{3\left(c_{1}\left(2 c_{2}\left(\varepsilon_{1}+\varepsilon_{2}\right)+\zeta\right)+c_{2} \zeta\right)}>0$. Since $b>0$ by assumption, the result in Proposition 3 follows. 


\section{Proof of Proposition 4}

The fact that $\left(\Pi^{A}\right)_{P F r}<\left(\Pi^{A}\right)_{S}$ for $0<b<b^{*}$ may also explain why the value of the welfare function $W$ under freely allocated permits is smaller than the value of the welfare function $W$ under emission standards for $0<b<b^{*}$. Let us rewrite $\Phi_{1, P^{F r} \text { and }} \Phi_{1, S}$, as follows:

$$
\begin{aligned}
& \Phi_{1, P^{F r}}=\left(\frac{E^{N}-E^{A}}{\phi_{1} \kappa_{1} \kappa_{2}}\right)^{\phi_{1}}\left(\frac{2 r\left(\phi_{1}-1\right)}{b\left[\left(Q^{N}\right)^{2}-\left(Q^{A}\right)^{2}\right]+2\left[\Pi^{N}-\left(\Pi^{A}\right)_{P^{F r}}\right]+2 r K\left(E^{N}-E^{A}\right)}\right)^{\phi_{1}-1} \\
& \Phi_{1, S}=\left(\frac{E^{N}-E^{A}}{\phi_{1} \kappa_{1} \kappa_{2}}\right)^{\phi_{1}}\left(\frac{2 r\left(\phi_{1}-1\right)}{b\left[\left(Q^{N}\right)^{2}-\left(Q^{A}\right)^{2}\right]+2\left[\Pi^{N}-\left(\Pi^{A}\right)_{S}\right]+2 r K\left(E^{N}-E^{A}\right)}\right)^{\phi_{1}-1}
\end{aligned}
$$

It is immediate to show that $\Phi_{1, P F r}<\Phi_{1, S}$ if $0<b<b^{*}$. Let us consider the exponential term in (31) which accounts for the perpetual American option value. Then, substituting the expressions for $\Phi_{1, P^{F r}}$ and $\Phi_{1, S}$ into the option term and comparing the two values, we find that the value of the option to reduce emission under freely allocated permits is smaller than the value of the option to reduce emission under emission standards for $0<b<b^{*}$. As before, the objective function $W$ (as of $t=0$ ) should not be interpreted as the option value alone but as the social welfare function that includes the value arising from the welfare prior to the environmental policy adoption plus the option to implement an environmental policy. By comparing the two value functions the result in Proposition 4 follows.

\section{Appendix B}

Derivation of the critical threshold $\tilde{\theta}_{k}, T, S, P^{A u}$ and $P^{F r}$

In this Appendix we derive the optimal timing for the environmental policy $v$ when the regulator uses the accrued revenues to finance public abatement activities. In this framework, the value function for the no-adopt region, $W_{v}^{N}(\theta, M)$ must satisfy the Hamilton-Jacobi-Bellman equation:

$$
r W_{v}^{N}=B^{N}(\theta, M)+\left(E^{N}-\delta M\right) \frac{\partial W_{v}^{N}}{\partial M}+\alpha \theta \frac{\partial W_{v}^{N}}{\partial \theta}+\frac{1}{2} \sigma^{2} \theta^{2} \frac{\partial^{2} W_{v}^{N}}{\partial \theta^{2}},
$$

which has the following solution:

$$
W_{v}^{N}(\theta, M)=\tilde{\Phi}_{1, v} \theta^{\phi_{1}}+\left[\frac{b\left(Q^{N}\right)^{2}}{2 r}+\frac{\Pi^{N}}{r}-\frac{\theta M}{\kappa_{2}}-\frac{\theta E^{N}}{\kappa_{1} \kappa_{2}}\right]
$$

where $\phi_{1}$ is the positive solution to the standard characteristic equation. 
The value function for the adopt region, $W_{v}^{A}(\theta, M)$, can be calculated directly as:

$$
\begin{aligned}
W_{v}^{A}(\theta, M) & =\mathbb{E}\left\{\int_{0}^{\infty} e^{-r t} B_{v}^{A}\left(\theta_{t}, M_{t}\right) d t\right\} \\
& =\int_{0}^{\infty} e^{-r t}\left[C S^{A}+\left(\Pi^{A}\right)_{v}\right] d t-\int_{0}^{\infty} e^{-r t} \theta e^{\alpha t}\left[\frac{l^{A}}{\delta}+\left(M-\frac{l^{A}}{\delta}\right) e^{-\delta t}\right] d t \\
& =\frac{b\left(Q^{A}\right)^{2}}{2 r}+\frac{\left(\Pi^{A}\right)_{v}}{r}-\frac{\theta M}{\kappa_{2}}-\frac{\theta l^{A}}{\kappa_{1} \kappa_{2}} .
\end{aligned}
$$

where $l^{A}=\xi^{A}$ if $v=T$ and $P^{A u}$ and $l^{A}=E^{A}$ if $v=S$ and $P^{F r}$. The solutions for $W_{v}^{N}(\theta, M)$ and $W_{v}^{A}(\theta, M)$ must satisfy the following set of boundary conditions:

$$
\begin{gathered}
W_{v}^{N}(0, M)=0, \\
W_{v}^{A}(0, M)=0, \\
W_{v}^{N}\left(\tilde{\theta}_{v}, M\right)=W_{v}^{A}\left(\tilde{\theta}_{v}, M\right)-K\left(E^{N}-l^{A}\right),
\end{gathered}
$$

and:

$$
\frac{\partial W_{v}^{N}\left(\tilde{\theta}_{v}, M\right)}{\partial \theta}=\frac{\partial W_{v}^{A}\left(\tilde{\theta}_{v}, M\right)}{\partial \theta},
$$

where $\tilde{\theta}_{v}$ is the critical value of $\theta$ at or above which the optimal environmental policies should be adopted. The critical threshold $\tilde{\theta}_{v}$ and the value of $\tilde{\Phi}_{1, v}$ can be easily computed as in the previous section.

Proof of Propositions 6, 7 and 8

Propositions 6, 7 and 8 can be easily proved by following the same argument of the previous section. 